\title{
CONSERVAÇÃo DE PÊSSEgos 'BIUTI' POR IRRADIAÇÃO'
}

\author{
Luciana CALORE $2^{*}$, Rogério Lopes VIEITES ${ }^{3}$
}

\section{RESUMO}

Este trabalho teve como objetivo o emprego da radiação gama associada ou não à refrigeração na conservação pós-colheita dos pêssegos 'Biuti'. O comportamento destes frutos foi estudado através de análises físicas (perda de massa fresca, coloração da casca, índice de doença, conservação pós-colheita e firmeza) e químicas (pH, acidez total titulável (ATT), sólidos solúveis totais (SST) e o índice de maturidade, expresso pela relação SST/ ATT). Os frutos colhidos no estádio de maturação fisiológica receberam os seguintes tratamentos: 0,0kGy; 0,1kGy; 0,2kGy; 0,3kGy; 0,4kGy e 0,5kGy através do irradiador "GAMMABEAN 650" que tem como fonte o Cobalto 60. Os pêssegos foram armazenados em condições ambientais $\left(24 \pm 2^{\circ} \mathrm{C} ; 72-76 \%\right.$ UR) por 1 semana e em condições de refrigeração em estufa B.O.D. $\left(0 \pm 1^{\circ} \mathrm{C} ; 70-80 \%\right.$ UR) por 2 semanas. Analisando os resultados pode-se concluir que as diferentes doses de radiação aplicadas não promoveram o aumento da vida-útil pós-colheita de pêssegos. Os frutos armazenados sob refrigeração tiveram maior vida-útil póscolheita em relação aos armazenados em temperatura ambiente.

Palavras-chave: Prunus persica; qualidade; pós-colheita.

\section{SUMMARY}

CONSERVATION OF 'BIUTI' PEACH BY IRRADIATION. The purpose of this work was the use of gamma radiation associated or otherwise with refrigeration in the post-harvest conservation of the peach 'Biuti'. The behavior of these fruits was studied fromtheir physical analysis (fresh mass loss, peel color, fungus attack, post-harvest conservation and texture) and chemical analysis (pH, total titratable acidity (TTA), total soluble solids (TSS) and the maturity index (TSS/TTA). The fruits, picked at a physiological mature stage, received the following treatments: $0,0 \mathrm{kGy} ; 0,1 \mathrm{kGy} ; 0,2 \mathrm{kGy} ; 0,3 \mathrm{kGy} ; 0,4 \mathrm{kGy}$ and $0,5 \mathrm{kGy}$ using the "GAMMABEAN 650" irradiator using Cobalt 60. The peaches were stored under environmental conditions $\left(24 \pm 2^{\circ} \mathrm{C} ; 72-76 \% \mathrm{RH}\right)$ for 1 week and under refrigerated conditions inside a B.O.D. chamber $\left(0 \pm 1^{\circ} \mathrm{C} ; 70-80 \% \mathrm{RH}\right)$ for 2 weeks. The results showed that the different doses of gamma radiation did not extend the peach postharvest life. The fruits stored under refrigeration had the longest postharvest life as compared to those stored under environmental conditions.

Keywords: Prunus persica; quality; post-harvest.

\section{1 - INTRODUÇÃO}

Nos últimos anos, o consumo de frutos de caroço vem aumentando no Brasil. A produção nacional de pêssegos de mesa é ainda insuficiente, ficando em torno de 130 mil toneladas/ano, levando a um aumento significativo de importações. Em 1996, o Brasil importou 12 mil toneladas desta fruta, o equivalente à metade da produção do Estado de Santa Catarina na mesma época [16].

Dados disponiveis para o Brasil, indicam que parte da produção nacional de frutos e legumes é perdida, principalmente após a colheita, por falta de tratamento e manuseio adequados, vulnerabilidade ao ataque de microrganismos, e falta de estocagem frigorificada. Tais perdas pós-colheita variam entre 30 a 50\%. Esses valores representam um descarte aproximado de 15 milhões de toneladas/ano [7].

Assim, um manuseio pós-colheita adequado, associado a técnicas de conservação de alimentos deve ser empregado com a finalidade de prolongar a vida-útil de frutos e hortaliças, aumentando o período de comercialização.

\footnotetext{
Recebido para publicação em 08/08/2001. Aceito para publicação em 16/09/2003 (000720).

${ }^{2}$ UNICAMP/Faculdade de Engenharia Agricola-FEAGRI, Cx. Postal 6011 CEP 13083-970, Cidade Universitária "Zeferino Vaz" s/n, Campinas/ SP.lucalore@agr.unicamp.br

${ }^{3}$ UNESP/FCA - Departamento de Produção Vegetal Cx. Postal 237, CEP 18603-970, Botucatu/SP.

* A quem a correspondência deve ser enviada
}

Desse modo, a utilização de baixas temperaturas no armazenamento reduz a taxa metabólica dos processos de maturação e senescência precoce das frutas e retarda o desenvolvimento dos microrganismos que possam estar presentes [2].

Com a evolução dos processos tecnológicos de conservação de alimentos, observou-se há mais de meio século, que as radiações gama do Cobalto-60 ou do Césio-137 ou mesmo os elétrons acelerados são capazes de inibir a proliferação de microrganismos muitas vezes patogênicos que podem causar sérias doenças aos consumidores [12]. Como vantagem adicional, as radiações ionizantes induzem a pequenas alterações fisiológicas, principalmente em frutos, fazendo com que haja retardo nos processos de maturação. Isto prolonga sua vida-útil, incluindo aqui consideráveis vantagens econômicas [15].

De acordo com CHITARRA \& CHITARRA [5] a irradiação de frutos e hortaliças pós-colheita tem como principal interesse a redução ou retardo nos danos causados por doenças, atuando como fungicida. Contudo, é também utilizada como método de conservação, prolongando o armazenamento pelo retardo do amadurecimento e do brotamento de alguns produtos. O seu uso apresenta alguns inconvenientes, pois, dependendo da dosagem de radiação, pode ocorrer escurecimento, amaciamento, aparecimento de depressões superficiais, amadurecimento anormal e perda de aroma e sabor dos produtos.

Segundo WIENDL [22] assim como outras técnicas de processamento de alimentos, a irradiação pode cau- 
sar mudanças na composição química e no valor nutritivo. A natureza e a extensão destas mudanças dependem do tipo, variedade e composição do alimento, da dose de radiação recebida e das condições ambientais durante e após a irradiação.

Associada aos procedimentos pós-colheita normalmente empregados, as radiações gama, em baixos niveis de dose, têm mostrado ser um excelente método para prolongar a vida comercial das frutas, retardando os processos de amadurecimento e senescência, bem como reduzindo significativamente o apodrecimento causado por fungos e bactérias patogênicas [13].

Assim, este trabalho teve como objetivo avaliar o emprego da irradiação associada ou não à refrigeração, na conservação pós-colheita de pêssegos 'Biuti'.

\section{2 - MATERIAL E MÉTODOS}

Os pêssegos da cultivar 'Biuti' foram provenientes do municipio de Paranapanema/SP e colhidos no estádio de maturidade fisiológica, no qual ocorre crescimento máximo do fruto e mudança da coloração da casca de verde para amarelo-claro. Frutos com defeitos fisiológicos ou injúrias foram descartados. A seguir, os pêssegos foram levados até o Centro de Energia Nuclear na Agricultura (CENA/USP) em Piracicaba, onde receberam diferentes doses de raios gama através do irradiador "GAMMABEAN - 650" que tem como fonte o Cobalto-60. Utilizou-se as doses: 0,0kGy; 0,1kGy; 0,2kGy; 0,3kGy; 0,4kGy e ,05kGy.

Em seguida, os frutos foram armazenados em condições ambientais por 1 semana $\left(24 \pm 2^{\circ} \mathrm{C} ; 72-76 \%\right.$ UR) e sob refrigeração em estufa $\mathrm{BOD}\left(\mathrm{O} \pm 1^{\circ} \mathrm{C} ; 70-80 \% \mathrm{UR}\right)$ por 2 semanas.

Foram realizadas as seguintes análises físicas: perda de massa fresca, coloração da casca, indice de doença, conservação pós-colheita e a firmeza. A perda de massa fresca expressa em porcentagem, foi obtida através da relação entre o peso inicial do fruto e o peso no momento da amostragem. Determinou-se a cor da casca dos frutos por uma escala de notas variando de 1 a 5 , onde 1 =fruto verde; 2 =fruto mais verde que amarelo; $3=$ fruto verde e amarelo em partes iguais; $4=$ fruto mais amarelo que verde e 5 =fruto amarelo. À medida que foram sendo detectados frutos com sintoma inicial de doenças, os mesmos foram descartados, calculando-se a porcentagem da incidência de doenças. A conservação póscolheita foi calculada pelo número médio de dias em que os frutos se conservaram em função de sua qualidade comercial. A firmeza foi obtida pelo texturômetro STEVENS-LFRA Texture Analyser a uma distância de $20 \mathrm{~mm}$ e velocidade de $2 \mathrm{~mm} / \mathrm{s}$, expressando os resultados em gf $/ \mathrm{cm}^{2}$.

Também foram feitas análises químicas como o $\mathrm{pH}$, a acidez total titulável (ATT), os sólidos solúveis totais (SST), e o indice de maturidade. A determinação do $\mathrm{pH}$ foi realizada conforme técnica descrita pelo INSTITUTO ADOLFO LUTZ [10]. Determinou-se a acidez total titulável e os sólidos solúveis totais conforme recomendações fei- tas pela AOAC [1]. O índice de maturidade foi calculado pela relação SST/ATT.

O intervalo de amostragem foi diário para pêssegos mantidos em condições ambientais e a cada dois dias para os pêssegos refrigerados.

O delineamento experimental empregado foi o inteiramente casualisado, com 6 tratamentos e 3 repetições utilizando-se 3 frutos por repetição. Os dados obtidos foram submetidos à análise de variância, (Teste F) e para comparação entre as médias utilizou-se o teste Tukey a $5 \%$ de probabilidade, utilizando o programa estatístico SAS Institute.

\section{3 - RESULTADOS E DISCUSSÃO}

\section{1 - Característica físicas}

\subsection{1 - Perda de massa fresca}

Na Tabela 1 são apresentados os dados da perda de massa fresca diária, expressa em porcentagem, na qual verifica-se que tanto na refrigeração como nas condições ambientais de armazenamento, os frutos que receberam a dose $0,1 \mathrm{kGy}$ apresentaram as menores perdas de massa fresca, entretanto, estas perdas não diferiram estatisticamente da perda de massa fresca dos frutos do tratamento testemunha. Desta forma, a irradiação não mostrou efeito em diminuir a perda de massa fresca.

Estes dados encontram apoio em GERMANO; ARTHUR \& WIENDL [9] onde a irradiação em abacates nas doses de 25, 50, 75 e 100Gy e o armazenamento em temperatura ambiente e sob refrigeração, não apresentou efeito sobre a perda de massa fresca.

Entretanto, no armazenamento à temperatura ambiente, as perdas de massa fresca foram sempre superiores às condições de refrigeração, em todas as doses de radiação aplicadas. Segundo LEAL \& CORTEZ [14] a temperatura é considerada o fator ambiental mais importante na conservação de frutas e hortaliças, uma vez que afeta diretamente os processos de respiração e transpiração dos produtos hortícolas.

TABELA 1. Variação média percentual da perda de massa fresca de pêssegos 'Biuti' submetidos à radiação gama durante 14 e 7 dias de armazenamento refrigerado e ambiente, respectivamente.

\begin{tabular}{ccc}
\hline TRATAMENTOS & REFRIGERADO & AMBIENTE \\
\hline Testemunha & $1,55 \mathrm{Bb}$ & $2,09 \mathrm{Ab}$ \\
$0,1 \mathrm{kGy}$ & $1,51 \mathrm{Bb}$ & $2,01 \mathrm{Ab}$ \\
$0,2 \mathrm{kGy}$ & $1,86 \mathrm{Ba}$ & $2,35 \mathrm{Aa}$ \\
$0,3 \mathrm{kGy}$ & $1,60 \mathrm{Bb}$ & $2,22 \mathrm{Ab}$ \\
$0,4 \mathrm{kGy}$ & $1,94 \mathrm{Ba}$ & $2,25 \mathrm{Aa}$ \\
$0,5 \mathrm{kGy}$ & $1,89 \mathrm{Ba}$ & $2,36 \mathrm{Aa}$ \\
\hline
\end{tabular}

-Médias de tratamentos seguidas da mesma letra minúscula na coluna e maiúscula na linha não diferem significativamente entre si ao nivel de $5 \%$ de probabilidade pelo teste de Tukey.

\subsection{2 - Cor da casca}

Nos pêssegos mantidos sob refrigeração observou-se pequena variação na perda da coloração verde dos frutos 
em todas as doses de radiação aplicadas, atingindo nota máxima de 4 com a dose 0,2kGy, como mostrado na Tabela 2. Entretanto, os pêssegos que receberam as doses 0,1 e 0,3kGy apresentaram, no final do armazenamento, menor evolução na coloração da casca recebendo notas de 3,4 e 3,2, respectivamente, concordando com CALORE, GIANNONI \& VIEITES [4], que também verificaram em limas ácidas 'Tahiti' irradiadas nas doses 0,1 e 0,3kGy, coloração mais verde durante 21 dias de armazenamento.

Ao longo de 7 dias do armazenamento de pêssegos 'Biuti' em condições ambientais ocorreu mudança na coloração dos frutos de todos os tratamentos, atingindo nota máxima de 5, ou seja, passando de verde para amarelo-claro.

TABELA 2. Evolução da coloração da casca de pêssegos 'Biuti' submetidos à radiação gama e armazenados em condições de refrigeração e em condições ambientais.

\begin{tabular}{|c|c|c|c|c|c|c|c|c|c|c|c|c|c|c|}
\hline \multicolumn{8}{|c|}{ Armazenamento Refrigerado } & \multicolumn{7}{|c|}{ Ammazenamento Ambiente } \\
\hline \multirow[t]{2}{*}{ Tratamentos } & \multicolumn{7}{|c|}{ Dias de Análise } & \multicolumn{7}{|c|}{ Dias de Análise } \\
\hline & 2 & 4 & 6 & 8 & 10 & 12 & 14 & 1 & 2 & 3 & 4 & 5 & 6 & 7 \\
\hline Testemunha & 2,0 & 2,9 & 3,4 & 3,4 & 3,5 & 3,6 & 3,6 & 1,8 & 2,6 & 3,4 & 4,4 & 4,7 & 4,9 & 5,0 \\
\hline $0,1 \mathrm{kGy}$ & 2,1 & 2,7 & 3,2 & 3,2 & 3,2 & 3,4 & 3,4 & 1,7 & 2,1 & 2,8 & 4,0 & 4,4 & 4,6 & 4,7 \\
\hline $0,2 \mathrm{kGy}$ & 2,1 & 2,7 & 3,2 & 3,2 & 3,4 & 3,4 & 4,0 & 2,1 & 3,0 & 3,9 & 4,8 & 4,9 & 5,0 & 5,0 \\
\hline $0,3 \mathrm{kGy}$ & 1,7 & 2,3 & 3,0 & 3,1 & 3,1 & 3,1 & 3,2 & 1,5 & 2,4 & 3,6 & 4,1 & 4,8 & 5,0 & 5,0 \\
\hline $0,4 \mathrm{kGy}$ & 1,8 & 2,4 & 2,9 & 3,1 & 3,2 & 3,3 & 3,5 & 1,6 & 3,0 & 3,9 & 4,5 & 4,8 & 4,9 & 4,9 \\
\hline $0,5 \mathrm{kGy}$ & 1,9 & 2,6 & 3,2 & 3,2 & 3,3 & 3,4 & 3,5 & 1,5 & 2,8 & 4,1 & 4,8 & 5,0 & 5,0 & 5,0 \\
\hline
\end{tabular}

Escala de notas: 1 =fruto verde; $2=$ fruto mais verde que amarelo; $3=$ fruto verde $e$ amarelo em partes iguais; $4=$ fruto mais amarelo que verde e $5=$ fruto amarelo

Foram observados sinais de queimaduras na casca de pêssegos mantidos sob refrigeração a partir do $8^{\circ}$ dia de armazenamento, sendo mais severos nos frutos que receberam a dose 0,5kGy. Estes dados encontram apoio em DOMARCO et al. [8] os quais relataram que à medida que se elevaram as doses de radiação aplicadas em uva 'Itália', foi observado escurecimento das amostras.

Entretanto, estes sinais não foram observados nos frutos mantidos em condições ambientais. Assim, a associação da irradiação com a refrigeração levou ao aparecimento de injúrias na casca. CHITARRA \& CHITARRA [5] relatam que o uso da irradiação pode provocar o escurecimento, o amaciamento e depressões superficiais nos produtos, dependendo da dosagem aplicada.

\subsection{3 - Índice de doença}

O aparecimento de doenças foi registrado em apenas 1 fruto do tratamento testemunha (sem irradiação) armazenado em temperatura ambiente. Tal fruto doente foi submetido a exames fitopatológicos e confirmou-se a presença dos patógenos Monilia fructicola, causador da podridão parda, principal doença do pêssego, e do Colletotrichum sp, causador da antracnose. Dessa maneira, a radiação de frutos pós-colheita controlou o surgimento de patógenos nos pêssegos, concordando com CHITARRA \& CHITARRA [5] e KAFERSTEIN \& MOY [13].

Não foi detectado sintoma de doença durante o período experimental nos frutos mantidos sob refrigeração e que receberam as diferentes dosagens de radiação.
Desse modo, observa-se o efeito da radiação e refrigeração em combater doenças pós-colheita de frutas.

\subsection{4 - Conservação pós-colheita}

A Tabela 3 mostra o número de dias em que os frutos mantiveram-se em condições visuais aceitáveis de comercialização.

Em ambas temperaturas estudadas, as diferentes doses de radiação aplicadas não mostraram diferença significativa no periodo de conservação pós-colheita dos pêssegos, concordando com GERMANO, ARTHUR \& WIENDL [9], os quais relatam que não houve aumento significativo nos dias de vida-útil pós-colheita em abacates irradiados.

Os dados aqui apresentados discordam dos apresentados por ZEGOTA [23], que verificou aumento de 9 dias na vida-útil de morangos irradiados com a dose de 2,5kGy combinada com o armazenamento refrigerado. BLEINROTH [3], também verificou aumento de uma semana na conservação pós-colheita do mamão com as doses de 0,5 a 0,8kGy, quando comparada com a refrigeração convencional. Entretanto, os pêssegos submetidos ao armazenamento refrigerado tiveram maior vidaútil pós-colheita quando comparados com os pêssegos armazenados em condições ambientais, fato este também verificado por GERMANO, ARTHUR \& WIENDL [9] com abacates.

TABELA 3. Variação média de dias de conservação póscolheita de pêssegos 'Biuti' em função da sua qualidade comercial, submetidos à radiação gama e armazenados sob refrigeração e em condições ambientais.

\begin{tabular}{ccc}
\hline TRATAMENTOS & REFRIGERADO & AMBIENTE \\
\hline Testemunha & $14,90 \mathrm{Aa}$ & $8,00 \mathrm{Ba}$ \\
$0,1 \mathrm{kGy}$ & $15,20 \mathrm{Aa}$ & $9,20 \mathrm{Ba}$ \\
$0,2 \mathrm{kGy}$ & $14,80 \mathrm{Aa}$ & $8,60 \mathrm{Ba}$ \\
$0,3 \mathrm{kGy}$ & $15,00 \mathrm{Aa}$ & $8,40 \mathrm{Ba}$ \\
$0,4 \mathrm{kGy}$ & $14,70 \mathrm{Aa}$ & $8,10 \mathrm{Ba}$ \\
$0,5 \mathrm{kGy}$ & $14,60 \mathrm{Aa}$ & $8,10 \mathrm{Ba}$ \\
\hline
\end{tabular}

-Médias de tratamento seguidas da mesma letra minúscula na coluna e maiúscula na linha não diferem significativamente entre si ao nivel de 5\% de probabilidade pelo teste de Tukey

\subsection{5 - Firmeza}

Observou-se diminuição nos valores de firmeza dos frutos de todos os tratamentos ao longo do período de conservação. A perda da consistência dos frutos durante o armazenamento é um resultado da continuidade dos processos de maturação e amadurecimento [11].

No armazenamento refrigerado, os pêssegos do tratamento testemunha mantiveram-se mais firmes seguidos do tratamento com a dose 0,2kGy, concordando com (CALORE, GIANNONI \& VIETES [4] os quais trabalharam com limas ácidas 'Tahiti' irradiadas. SARZI, VIEITES \& DEL MASTRO [19] também verificaram maior eficiência na manutenção da firmeza de laranjas 'Pera' irradiadas com a dose 0,25kGy.

Já os frutos que receberam a dose 0,5kGy apresentaram valores de firmeza menos consistentes em relação à testemunha resultando em pêssegos mais amolecidos. 
Nas condições ambientais de armazenamento o tratamento com a dose 0,1kGy apresentou maior valor de firmeza até o 3o dia e a partir daí, os diferentes tratamentos não mostraram diferenças significativas.

\section{2 - Características químicas}

\subsection{1 - pH}

Todos os tratamentos mostraram redução significativa nos valores de $\mathrm{pH}$ no final do periodo estudado quando comparados com o período inicial. Estes dados revelam que a radiação aplicada em pêssegos 'Biuti' não interfere no comportamento do $\mathrm{pH}$ durante o processo de amadurecimento do referido fruto, uma vez que o tratamento testemunha (sem irradiação) teve comportamento semelhante aos demais.

Entre as diferentes doses aplicadas não houve uma relação direta ou inversamente proporcional com os valore de $\mathrm{pH}$. Estes dados são discordantes dos encontrados por DOMARCO et al. [8] os quais encontraram uma relação linear entre o pH e a dose de radiação aplicada em uva 'Itália'. Com o aumento da dose de radiação aplicada, o pH sofreu um acréscimo.

Comparando-se a variação do $\mathrm{pH}$ em pêssegos 'Biuti', OLIVEIRA [18] encontrou valores entre 2,70 a 3,30, indices bem próximos aos observados neste experimento.

\subsection{2 - Acidez total titulável}

De acordo com COELHO [6] o teor de ácidos orgânicos, em pêssegos, geralmente decresce após a colheita e durante o armazenamento a baixas temperaturas. Em contraste com esta citação, os resultados deste experimento mostram que pêssegos do cultivar 'Biuti' armazenados sob refrigeração e que receberam as diferentes doses de radiação, apresentaram valores maiores para a acidez no 14어 dia de armazenamento em relação ao período inicial, como pode ser visto na Tabela 4.

Já os frutos mantidos em condições ambientais de armazenamento apresentaram comportamento contrário ao dos pêssegos refrigerados, ou seja, observou-se tendência a valores de acidez total titulável decrescentes ao longo do periodo de armazenamento. Estes dados são semelhantes aos relatados por OLIVEIRA [18], o qual encontrou diminuição nos valores da acidez durante o armazenamento de pêssegos 'Biuti' em condições ambientais.

VIEITES [21] e DOMARCO et al. [8] também verificaram decréscimo no teor da acidez total titulável em tomate e uva 'Itália' irradiados.

CHITARRA \& CHITARRA [5] relatam que o teor de ácidos orgânicos, com poucas exceções, diminui com a maturação, em decorrência do processo respiratório ou de sua conversão em açúcares. Deste modo, no final do armazenamento em condições ambientais, os frutos dos tratamentos testemunha (sem irradiação) e com a dose 0,1 kGy apresentaram valores mais altos de acidez quando comparados com os demais tratamentos, indicando amadurecimento mais lento nestes frutos. Visto que não houve diferença entre a testemunha e a dose
0,1kGy, pode-se afirmar que a irradiação não mostrou efeito no retardo do amadurecimento destes frutos quanto a este parâmetro.

TABELA 4. Variação média da acidez total titulável (g ácido cítrico $100 \mathrm{~g}^{-1}$ de polpa) de pêssegos 'Biuti' submetidos à radiação gama e armazenados em condições de refrigeração e em condições ambientais.

\begin{tabular}{|c|c|c|c|c|c|c|c|c|c|c|c|c|c|c|}
\hline & \multicolumn{7}{|c|}{ Armazenamento Refrigerado } & \multicolumn{7}{|c|}{ Armazenamento Ambiente } \\
\hline \multirow[t]{2}{*}{ Tratamentos } & \multicolumn{7}{|c|}{ Dias de Análise } & \multicolumn{7}{|c|}{ Dias de Análise } \\
\hline & 2 & 4 & 6 & 8 & 10 & 12 & 14 & 1 & 2 & 3 & 4 & 5 & 6 & 7 \\
\hline Testemunha & $0,80 \mathrm{~d}$ & $0,91 \mathrm{a}$ & $0,80 \mathrm{~d}$ & $0,82 \mathrm{~d}$ & 1,01a & $0,97 \mathrm{~b}$ & $0,97 \mathrm{~b}$ & $0,88 \mathrm{a}$ & $0,72 \mathrm{a}$ & $0,80 \mathrm{~b}$ & $0,81 \mathrm{a}$ & $0,72 \mathrm{~b}$ & $0,72 \mathrm{a}$ & $0,62 \mathrm{a}$ \\
\hline $0,1 \mathrm{kGy}$ & $0,79 \mathrm{e}$ & $0,80 \mathrm{e}$ & $0,87 \mathrm{a}$ & $0,88 \mathrm{~b}$ & $0,96 \mathrm{c}$ & $0,95 \mathrm{c}$ & $0,97 \mathrm{~b}$ & $0,78 \mathrm{bc}$ & $0,74 \mathrm{a}$ & $0,87 \mathrm{a}$ & $0,73 \mathrm{~b}$ & $0,82 \mathrm{a}$ & $0,63 \mathrm{c}$ & $0,63 \mathrm{a}$ \\
\hline $0,2 \mathrm{kGy}$ & $0,85 \mathrm{~b}$ & $0,85 \mathrm{~d}$ & $0,82 \mathrm{~b}$ & $0,85 \mathrm{c}$ & $0,97 \mathrm{~b}$ & $0,99 \mathrm{a}$ & $1,01 \mathrm{a}$ & $0,78 \mathrm{bc}$ & $0,73 \mathrm{a}$ & $0,66 \mathrm{e}$ & $0,7 \mathrm{llb}$ & $0,74 \mathrm{~b}$ & $0,67 \mathrm{~b}$ & $0,54 \mathrm{c}$ \\
\hline $0,3 \mathrm{kGy}$ & $0,87 \mathrm{a}$ & $0,79 \mathrm{f}$ & $0,82 \mathrm{~b}$ & $0,89 \mathrm{a}$ & $0.91 \mathrm{~d}$ & $0,88 \mathrm{e}$ & $0,92 \mathrm{c}$ & $0,79 \mathrm{~b}$ & $0,65 \mathrm{~b}$ & $0,71 \mathrm{~d}$ & $0,67 \mathrm{c}$ & $0,73 \mathrm{~b}$ & $0,63 \mathrm{c}$ & $0,57 \mathrm{~b}$ \\
\hline $0,4 \mathrm{kGy}$ & $0,81 \mathrm{c}$ & $0,88 \mathrm{~b}$ & $0,8 \mathrm{lc}$ & $0,89 \mathrm{a}$ & $0,66 \mathrm{f}$ & $0,89 \mathrm{~d}$ & $1,01 \mathrm{a}$ & $0,76 \mathrm{c}$ & $0,72 \mathrm{a}$ & $0,74 \mathrm{c}$ & $0,71 \mathrm{~b}$ & $0,72 \mathrm{~b}$ & $0,63 \mathrm{c}$ & $0,58 \mathrm{~b}$ \\
\hline $0,5 \mathrm{kGy}$ & $0,81 \mathrm{c}$ & $0,86 \mathrm{c}$ & $0,78 \mathrm{e}$ & $0,70 \mathrm{e}$ & $0,81 \mathrm{e}$ & $0,75 \mathrm{f}$ & $0,90 \mathrm{~d}$ & $0,78 \mathrm{bc}$ & $0,66 \mathrm{~b}$ & $0,68 \mathrm{e}$ & $0,66 \mathrm{c}$ & $0,63 \mathrm{c}$ & $0,60 \mathrm{~d}$ & $0,52 \mathrm{c}$ \\
\hline $\mathrm{CV}(\%)$ & 0,334 & & & & & & & 1,366 & & & & & & \\
\hline
\end{tabular}

- Médias de tratamentos seguidas da mesma letra não diferem significativamente entre si ao nivel de $5 \%$ de probabilidade pelo teste de Tukey.

\subsection{3 - Sólidos solúveis totais}

Verificou-se um aumento significativo nos teores de sólidos solúveis totais ao longo do periodo de armazenamento em todos os tratamentos, embora pequenas oscilações tenham ocorrido.

Os pêssegos refrigerados e que receberam a dose $0,3 \mathrm{kGy}$ apresentaram valores significativamente inferiores de sólidos solúveis totais em relação à testemunha, exceto no 6o e 8 dias de armazenamento, fato este discordante de NEVES, VIEITES \& GIANNONI [17] os quais relataram que a dose $0,1 \mathrm{kGy}$ manteve os mais baixos indices de sólidos solúveis totais em maçãs 'Gala'. Já os pêssegos submetidos à dose 0,5kGy apresentaram valores de sólidos solúveis totais mais altos que a testemunha, com exceção do 10 e 12을 dias de armazenamento, indicando amadurecimento e início de senescência mais rápidos. DOMARCO et al. [8] não encontraram efeito significativo entre as doses de radiação aplicadas em uva 'Itália' e os teores de sólidos solúveis totais.

Nas condições ambientais de armazenamento notase que os valores de sólidos solúveis totais tenderam ao acréscimo em todos os tratamentos, porém, os valores máximos obtidos foram observados no 7 ㅇ dia para o tratamento testemunha, no 6 dia para as doses 0,1 e 0,4kGy, no 4o dia para a dose 0,2kGy, no 3 dia para a dose $0,3 \mathrm{kGy}$ e no 2 - dia de armazenamento para a dose 0,5kGy. Assim, uma posterior redução no teor de sólidos solúveis totais pode ser explicada pelo amadurecimento natural dos frutos em função da entrada na senescência. Desse modo, a irradiação gama, de acordo com os resultados desse experimento para sólidos solúveis totais é ineficaz no retardo do amadurecimento de pêssegos 'Biuti', quando comparado à testemunha.

\subsection{4 - Índice de maturidade}

Em ambas condições de armazenamento (refrigerado e ambiente) ocorreu aumento no indice de maturida- 
de (SST/ATT, ou "Ratio") em todos os tratamentos comparando-se o periodo inicial com o final, dados estes concordantes com VIEITES [21].

A relação (SST/ATT) aumenta com o amadurecimento devido ao decréscimo na acidez, fato que permite uma relação elevada [5].

Os frutos mantidos sob refrigeração e que receberam as doses 0,3 e 0,4kGy apresentaram no 14을 valores de "Ratio" estatisticamente inferiores aos demais tratamentos, indicando a eficiência destas doses no retardo do amadurecimento dos frutos, dados concordantes com a UNITED FRESH FRUIT - VEGETABLE ASSOCIATION [20] a qual relata o uso da radiação ionizante no manuseio pós-colheita de frutas e hortaliças.

No final do período de conservação dos pêssegos mantidos em condições de armazenamento ambiente, a dose 0,1 kGy mostrou valores de "Ratio" significativamente inferior aos demais tratamentos, concordando com NEVES, VIEITES \& GIANNONI [17] os quais encontraram menor valor de "Ratio" com a dose 0,1kGy em maçãs 'Gala'. DOMARCO et al. [8] encontraram aumento na relação SST/ATT com o aumento das doses de radiação aplicadas em uva 'Itália'.

\section{4 - CONCLUSÕES}

A irradiação de pêssegos 'Biuti' na pós-colheita não promoveu o aumento da vida-útil pós-colheita. O aumento da vida-útil pós-colheita de pêssegos foi obtido com o uso da refrigeração.

A refrigeração proporcionou melhor conservação pós-colheita de pêssegos 'Biuti' em relação ao armazenamento ambiente.

As diferentes doses de radiação gama aplicadas em pêssegos 'Biuti' não interferiram no processo de retardo do amadurecimento dos mesmos.

\section{5 - REFERÊNCIAS BIBLIOGRÁFICAS}

[1] ASSOCIATION OF OFFICIAL ANALYTICAL CHEMISTRY. Official Methods as Analysis of the Association of Official Analytical Chemistry. 11ed. Washington, 1015 p. 1970.

[2] BLEINROTH, E. W. Recomendações para Armazenamento. Toda Fruta, v.1, n.5, p.34-37, 1986.

[3] BLEINRoth, E. W. Determinação do Ponto de Colheita. In: GAYET, J. P.; BLEINROTH, E. W.; MATALLO, M.; GARCIA, E. E. C.; GARCIA, A. E.; ARDITO, E. F. G.; BORDIN, M. R. Mamão para exportação: procedimentos de colheita e pós-colheita. Brasília: EMBRAPA, 1995. p. 10-25.

[4] CAlore, L.; GIANNONI, J. A.; VIEITES, R. L. Caracterização Físico-Química da Lima Ácida 'Tahiti' com o Uso da Radiação Gama. I Simpósio Internacional de Fruticultura, Botucatu, SP, 15-18 de março de 1999.

[5] CHITARRA, M. I. F.; CHITARRA, A. B. Armazenamento. In: __ Pós-colheita de frutos e hortaliças - fisiologia e manuseio. Lavas: ESAL/FAEPE, 1990. Cap.6, p. 143-98.
[6] COELHo, A. H. R. Qualidade Pós-Colheita de Pêssegos. Informe Agropecuário, v.17, n.180, p.31-9, 1994.

[7] DI RIENZO, C. A importância das Câmaras Frias na Horticultura. Tecnologia da Refrigeração, n.5, p.16$22,2001$.

[8] DomARCo, R. E.; SPoto, M. H. F.; BLUMER, L.; WALDER, J. M. M. Sinergia da Radiação Ionizante e do Aquecimento na Vida de Prateleira da Uva 'Itália'. Scientia Agrícola, v.56, n.4, p. , 1999.

[9] GERMANO, R. M. de A.; ARTHUR, V.; WIENDL, F. M. Conservação Pós-Colheita de Abacates Persia americana Mill, Variedades Fortuna e Quintal por Irradiação. Scientia Agrícola, v.53, n.2-3, p. , 1996.

[10] INSTITUTO ADOLFO LUTZ. Normas Analíticas: métodos físicos e químicos para análise de alimentos. 3ed. São Paulo: Instituto Adolfo Lutz, 1985, 533p.

[11] KADER, A. A. Fruit Maturity, Ripening, and Quality Relationships. Acta Horticulture, n. 485, p.203-8, 1999.

[12] KAFERSTEIN, F. K. Safe food more needed than ever before. Geneve: World Health Organization, 1993. 22p.

[13] KAFERstein, F. K.; MOY, G. G. Public Health Aspects of Food Irradiation. Journal of Public Health Policy, v. 14, n.2, p.149-163, 1993.

[14] LEAL, P. A. M.; CORTEZ, L. A. B. Métodos de PréResfriamento de Frutas e Hortaliças. II Curso de Atualização em Tecnologia de Resfriamento de Frutas e Hortaliças. Campinas: FEAGRI, 1998. p.81-115.

[15] LOAHARANU, P. Cost Benefit Aspects of Food Irradiation. Food Technology, v.48, n.1, p.104-108, 1994.

[16] NAKASU, B. H.; RASEIRA, M. C. B.; CASTRO, L. A. S. Frutas de Caroço: pêssego, nectarina e ameixa no Brasil. Informe Agropecuário, v. 18, n. 189, p.8-13, 1997.

[17] NEVES, L. T. B. C.; VIEITES, R. L.; GIANNONI, J. A. Utilização da Radiação Gama na Pós-Colheita de Frutos da Macieira, Armazenados sob Refrigeração. IX Congreso Latino-Americano de Horticultura, Santiago, 30 de novembro-03 de dezembro de 1998.

[18] OliveirA, M. A. de. Comportamento Pós-Colheita de Pêssegos (Prunus persica L. Batsch) Revestidos com Filmes a Base de Amido como Alternativa à Cera Comercial. Botucatu, 2000. 93p. Tese (Doutor em Agronomia/Horticultura) - Faculdade de Ciências Agronômicas, Universidade Estadual Paulista (UNESP).

[19] SARZI, B.; VIEITES, R. L.; DEL MASTRO, N. L. Efeito da Radiação Gama na Qualidade Pós-Colheita da Laranja 'Pera'. I Simpósio Internacional de Fruticultura, Botucatu, SP, 15-18 de março de 1999.

[20] UNITED FRESH FRUIT VEGETABLE ASSOCIATION. Food Irradiation for the Produce Industry. Alexandria, 1986. $11 \mathrm{p}$.

[21] VIEITES, R. L. Conservação Pós-Colheita do Tomate Através do Uso da Radiação Gama, Cera e Saco de Polietileno, Armazenados em Condições de Refrigeração e Ambiente. Botucatu, 1998. 131p. Tese (LivreDocência) - Faculdade de Ciências Agronômicas, Universidade Estadual Paulista (UNESP).

[22] WIENDL, F. M. A Salubridade dos Alimentos Irradiados. Boletim da Sociedade Brasileira de Ciência e Tecnologia de Alimentos, v.18, n.1, p.48-56, 1984.

[23] ZEGOTA, H. Suitability of 'Dukat' Strawberries for Studying Effects on Shelf Life of Irradiation Combined with Cold Storage. Zeitschrift fuer Lebensmittel Untersuchung und - Forschung, v.187. n.2, p.1114, 1988. 